\title{
Exposure Work Commuting: Case Study among Commuting Accidents in Klang Valley, Malaysia
}

\author{
Nurulhuda Binti Jamaluddin ${ }^{1}$, Ho Jen $\operatorname{Sim}^{1}$, Akmalia Shabadin ${ }^{1}$, Nusayba Megat Johari ${ }^{1}$ and Wahida Ameer \\ Batcha $^{2}$ \\ 1. Road Safety Engineering and Environment Research Centre, Malaysian Institute of Road Safety Research, Selangor 43000, \\ Malaysia \\ 2. Vehicle Safety and Biomechanics Research Centre, Malaysian Institute of Road Safety Research, Selangor 43000, Malaysia
}

\begin{abstract}
Traffic accidents caused the most accidental deaths at work in Malaysia. The SOCSO (Social Security Organization) reported that the number of deaths due to commuting accidents was 760 , nearly two times more than deaths caused by accidents that happened at the workplace (471 deaths). The aim of this study is to investigate the relationship of socio-demographic background and the risk exposure of the drivers during their work commuting trips. The study was based on compensation claims to SOCSO where data were extracted from "Form 21" provided by SOCSO. A total of 377 respondents were selected through systematic random sampling method from a list of SOCSO claimants. It was found that majority of the traffic accidents $(83 \%)$ involved males and most of them $(92.2 \%)$ were on motorcycles. Male drivers have an average driving experience of 10.7 years and 8.6 years for females. The estimation of the travelled distance for the sample from home to the workplace is $0.65 \sim 131 \mathrm{~km}$. Mean accident occurrence time was 23 min whilst mean distance was $11.6 \mathrm{~km}$. The multiple regression analysis showed that the accident distance was affected by the age of driver, actual travel distance, travel objective and speed.
\end{abstract}

Key words: Commuting accident, gender, age, exposure.

\section{Introduction}

Traffic accident injury has become a major issue in public health problems. In 2004, WHO (World Health Organization) [1] reported, in low-income and middle-income countries, about $85 \%$ of deaths and $90 \%$ of the annual DALYs (disability-adjusted life years) lost because of road traffic injury. In 2009, WHO [2] reported 139,156 deaths in western Pacific region and Malaysia have contributed more than 6,000 deaths. The study of all work-related fatalities was established worldwide.

In Australia, more comprehensive data on road deaths related to work were collected from the year 1989 [3]. Salminen [4] from Finland has derived the annual proportion of work-related traffic deaths of all

Corresponding author: Nurulhuda Binti Jamaluddin, M.Sc., researcher, research field: road safety. E-mail: nurulhuda@miros.gov.my. accidental deaths which varied from $38 \%$ to $63 \%$. In United Kingdom, the annual losses due to worker killed or injured on road is pound sterling 3.5 billion. Clarke [5] reported the drivers who drive on business purpose are at average risk of accident involvement relative to the general driving population. Chapman [6] found that the business mileage criteria shows important differences in self-reported driving behaviours, accident frequency and in the types of accident reported. Mileage is one of the indicators of exposure. It is considered as a relevant exposure measure.

Exposure data are used to evaluate road safety intervention and to determine the road safety level in the entire country. Exposure also has been used to explain that certain group of users are exposed to a higher risk of accidents. Exposure refers to the amount of travel in which accident may occur [7, 8]. The more we travel, the higher probability of an accident occurs. 
Although traffic injury was not included in the study, Gera and Kuhn [9] covered occupation and journey to work, focusing on economic factor in a journey made.

Thus, the present study sought to analyse the socio-demographics and socio-economics background of the victim, and to analyse the exposure of drivers involved in traffic accidents during their commute to and from the workplace.

\section{Commuting Accident in Malaysia}

SOCSO (Social Security Organisation) was established as a government department to enforce the Employee Social Security Act 1969. SOCSO administers the Employment Injury Insurance Scheme which is protection for employees against industrial accidents including occupational diseases and accidents while travelling for work related purpose.

SOCSO in 2009 reported that 20,810 of its contributors had been involved in accidents whilst commuting to work [10]. RPM (Royal Police Malaysia) [11] also reported the casualities of motorcyclist while work is 8,123 which is $39 \%$ of the commuting accidents. The commuting accidents which occurred during 6:01 to 8:00 a.m. and 6:01 to 8:00 p.m. refer to all the accidents occurring while travelling from/to place of work during authorized rest time or any period related work. Fig. 1 shows that the percentage of commuting accident from 2002 to 2009 increases as opposed to the industrial accidents. From the data, it was reported that the commuting accidents increased by $9.29 \%$ compared to 2008 . In terms of number of deaths, the commuting accidents increased by 760 , nearly two times of deaths due to industrial accidents (471 deaths). The results also noted that $60 \%$ of total deaths reported by the SOCSO were motorcyclists.

\section{Methods}

\subsection{Procedure}

This study is based on data from the SOCSO claimants of 2009 and 2010 in Klang Valley. Four hundred and seventy respondents who survived traffic accidents were selected through systematic random sampling method from list of SOCSO claimants. There were 93 traffic accidents whilst the person was at work and 377 traffic accidents occurring as the person was on the way to or from work. In this article, only commuting accidents were examined.

The source of data was primarily based on the accident claimer of Form 21 (accident report) used by SOCSO for all accident claimers throughout the country. From the total of 35 variables available in Form 21, information of employer, information of the respondent and the information of the accident history were obtained. Due to ethical consideration, all information would remain confidential. Fig. 2 shows the example of Form 21, available in Bahasa Melayu, the national language in Malaysia.

Variables such as age, gender, contact number, race, occupation, driving experience, travel purpose, date of accident, time start journey, time of accident, mode of transport, origin address, destination address and accident location can be determined from Form 21.

The data were extracted and transferred to the SPSS (Statistical Package for the Social Sciences) for analysis purpose. A brief analysis of the exposures, such as crash/100,000 $\mathrm{km}$ travelled, risk by demographic characteristics and other descriptive analysis can also be derived from the data.

\subsection{Data Analysis}

The estimation length of the kilometre travelled, determined by the origin address, accident location and

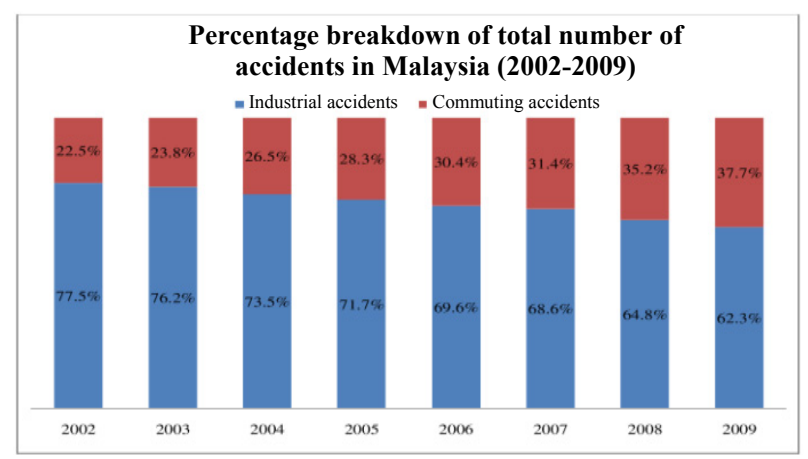

Fig. 1 Percentage of total number of accident (2002-2009). Source: Report of Industrial and Commuting Accident 2009 [12]. 


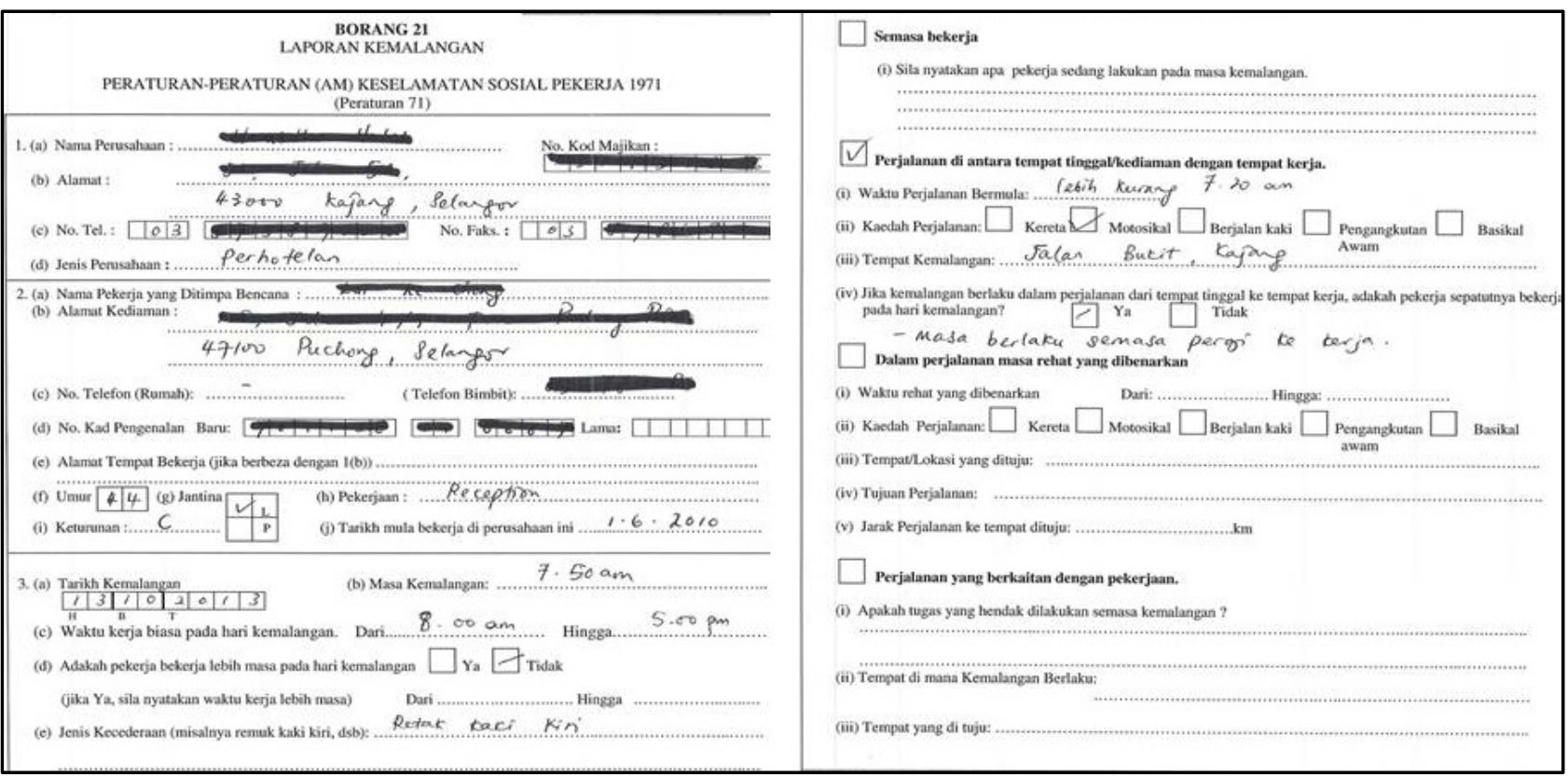

Fig. 2 Example of the Form 21.

destination address collected from Form 21 is obtained by the use of Google map application. Through this, the kilometre travel for each of respondent can be estimated. Similarly, the period of the journey to where the accident occurs is obtained by subtracting the time of accident from the time of departure.

The multiple regression analysis was used to assess the relationship between dependent variable (accident distance) and among several predictor variable. Multiple regression helps in choosing a few predictor variable related with the accident distance.

\section{Results}

\subsection{Description of the Samples}

The majority of the samples were males (83\%). The age of samples ranged from 19 years old to 77 years old. Samples reported a mean of 10.5 years of driving experience where males had significantly more time as a licensed driver (mean of 10.7 years) than females (mean of 8.6 years). Most of the samples travel $10 \mathrm{~km}$ to $20 \mathrm{~km}$ from origin to destination. Fig. 3 shows the frequency of the sample by the commuting exposure.

Motorcycle was the main type of vehicles involved in accident (92.2\%) followed by motorcar (5\%) and other (public transport and walking 2.7\%). Most of the samples worked in manufacturing sector $(35.5 \%)$, trading sector (12.5\%) and civil services (11.7\%).

\subsection{Mean Actual Distance Travelled}

Sample refers to the victim in a traffic accident. The estimated travelled distance for the sample from home to the workplace is $0.65 \mathrm{~km}$ to $131 \mathrm{~km}$. Mean accident occurrence time was $23 \mathrm{~min}$ whilst mean distance was $11.6 \mathrm{~km}$.

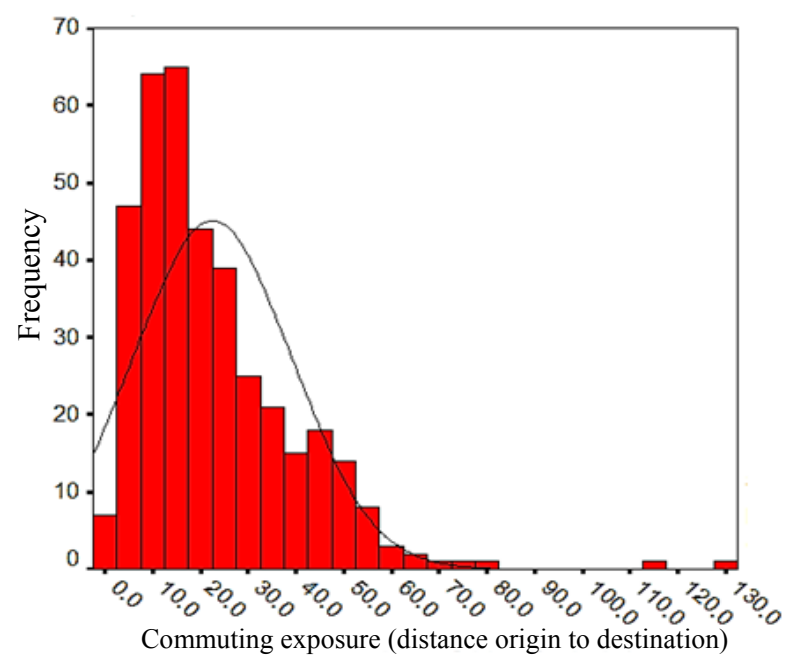

Fig. 3 Frequency of the commuting exposure. 
Several studies [4, 9] have noted that there are relationships between travel distance, occupation and traffic accident during commuting. Evidences have shown that blue-collar groups tend to use motorcycle to travel to work, often becoming the victim of traffic accidents. In acknowledging the increasing pressure due to increasing cost of living standard, there is also a growing trend of white-collar groups switching to motorcycle as a mode of transport.

In this study, the respondents were classified into seven groups (A to $G$ ) according to their occupation, under two main categories. The mean of actual distance travelled to work trips is given discretely by gender and occupation group in Table 1.

In general, it was found that white-collar group travelled farther as compared the blue-collar status group. Among the male respondents, the longest distance travelled is by Group C, followed by Groups A and B, while relatively short distance were travelled by the four lowest status groups (D, E, F and G). As for their female counterpart, professional group made an average of $16.8 \mathrm{~km}$ to their workplace.

\subsection{Multiple Regression Results}

Mentioned in the methodology section, a multiple regression analysis was performed to examine the relationship of actual travel distance (from origin to work/home) and accident distance. Ten explanatory variables, as shown in Table 2, were tested for their contributing effects on the accident location. The intention is to understand whether the distance of accident from origin is affected by total distance from home, age, type of vehicles and time of accident as well as travel speed.

Table 1 Mean distance travelled at the home to work by occupational group and gender.

\begin{tabular}{|c|c|c|c|c|}
\hline \multirow{2}{*}{ Occupational group } & & \multicolumn{3}{|c|}{ Mean distance travelled $(\mathrm{km})$} \\
\hline & & Male & Female & Both \\
\hline \multirow{4}{*}{ White-collar group } & $\begin{array}{l}\text { Group A: professional and high level } \\
\text { management }\end{array}$ & 25.3 & 16.8 & 23.4 \\
\hline & Group B: technicians and middle management & 27.3 & 24.9 & 27.0 \\
\hline & Group C: supervisor and foremen & 33.1 & 20.3 & 32.0 \\
\hline & Group D: skilled clerical-sales-service & 20.6 & 18.0 & 20.2 \\
\hline \multirow{3}{*}{ Blue-collar group } & Group E: production worker & 16.8 & 13.1 & 15.4 \\
\hline & Group F: machine operator & 21.2 & 23.5 & 21.4 \\
\hline & Group G: general worker & 18.6 & 11.9 & 18.2 \\
\hline
\end{tabular}

Table 2 Multiple regression analysis.

\begin{tabular}{|c|c|c|c|c|}
\hline & \multicolumn{2}{|c|}{ Unstandardized coefficients } & \multirow{2}{*}{$t$-statistics ${ }^{\mathrm{c}}$} & \multirow{2}{*}{$P$-value $\mathrm{d}^{\mathrm{d}}$} \\
\hline & $\beta^{\mathrm{a}}$ & $S \cdot E^{\mathrm{b}}$ & & \\
\hline Constant & -5.453 & 5.721 & -0.953 & 0.341 \\
\hline Age & 0.152 & 0.076 & 2.005 & $0.046^{*}$ \\
\hline Driving/riding experience & -0.060 & 0.088 & -0.683 & 0.495 \\
\hline Actual distance & 0.460 & 0.034 & 13.705 & $0.000^{*}$ \\
\hline Gender & 1.822 & 1.306 & 1.395 & 0.164 \\
\hline Type of vehicle: motorcycle & -4.051 & 5.378 & -0.753 & 0.452 \\
\hline Type of vehicle: motorcar & -0.309 & 5.834 & -0.053 & 0.958 \\
\hline Occupational status & 0.911 & 0.981 & 0.929 & 0.354 \\
\hline Travel objective & 2.092 & 0.946 & 2.211 & $0.028^{*}$ \\
\hline Time of accident & 0.323 & 0.998 & 0.324 & 0.746 \\
\hline Speed & 0.106 & 0.016 & 6.650 & $0.000 *$ \\
\hline
\end{tabular}

${ }^{\mathrm{a}}$ Parameter estimate for variables in the model (logistic regression model); ${ }^{b}$ standard error which explain the variance of each variables in the model; ${ }^{c}$ the statistics value of each variable; ${ }^{d}$ the significant statistics for each variable; * significant at 0.05 level. 
The results of the analysis suggest a relatively strong relationship as explained by the model $R^{2}=0.636$ with four significant explanatory predictors. The model is as follows:

DistA $=0.152 \mathrm{Age}+0.460$ Dist +2.092 Travel objective +0.106 Speed

where:

DistA is the accident distance travelled;

Dist is the actual distance travelled;

Age is age of the workers;

Travel objective is the purpose of the travelled;

Speed is average speed during the journey.

The accident location is strongly related to the travel objective reflecting that the trip heading to work is risker compared to the after work trip. Age group, distance between origin and destination and travel speed appeared to be significant in the model suggest that there are substantial effects from the surrounding environment on the accident travel risk. It was evident that motorists (especially young motorists) are prompted to travel at higher speeds when the travel distance is longer.

Surprisingly, the type of vehicles (motorcycle and motorcar) did not display any significant effect on the accident location. This may be attributed to the imbalance sample of motorcar and motorcycle in the analysis. Similarly, the occupational status did not appear to be significant. The effect may be compounded by the actual travel distance as it was found that the travel distance is related to the occupational status (as explained above).

\section{Discussions and Conclusions}

The sample size for this study was based on the sample through SOCSO data, thus, it was not perfectly reflected in the real scenario. Male and motorists dominated the sample size and fewer representatives from the high risk accident group which is between 15 to 25 years old were acquired. Nevertheless, these results are still deemed important as it provides insights into the causal factors of work commuting injury.
More extensive studies will be carried out to include further explanatory factors with a larger pool of respondents. The results provide evidences that are worth exploring further:

(1) Female tends to travel shorter compared to their male counterpart. The gender composition in the workforce is an important factor in contributing accident location;

(2) Occupational status was found to have effect on the distance of travel. This is a useful insight as the lower occupational status groups tend to live in mixed-development areas where the living standard is lower. In Malaysia, the industrial areas are usually built around the suburban area. From this fact, the exposures of the lower occupational status led them to live close to their workplace. This indirectly decreases their exposure but increases their risk of accident due to influence of the environment and mode choice. It is reported that the car insurance rates depend on home address due to that most accidents occur closer to homes due to the risk being higher than the long distance journey. Spatial distribution of employment opportunity and residential hereby should be planned properly in the future;

(3) Factors such as age group, travel objective, travel distance and speed, were found to positively affect the accident location. However, further study needs to be conducted to look into other factors such as road environment, type of road travelled and traffic condition which may also influence risk of accident.

The results of this study were found consistent with other studies on the exposure and risk of the motorists. While distance of accident showed a positive correlation with actual distance traveled, this study was unable to generate any evidence on the accident risk increase with the mileage/exposure. This brought to the consideration of possible confounded effect with occupational status. If this hypothesis (negative relationship between occupational status and travel distance) is true, target should be set to improve accessibility of local movement such as 
motorcycle/bicycle lane, pedestrian walk path and efficient public transport.

The identification of age and average travel speed to be significant causal factors suggests that the relevant authorities to design appropriate intervention measures aim at reducing the severity of injury. In particular, the priority of intervention program should target young motorists.

It is noted that the over-representation of motorcycle in this study may contribute to a biased interpretation of actual traffic composition (where motorcycle constitutes $60 \%$ of total traffic volume) in Malaysia.

Further exploration is needed where other additional attributes such as demographic, land use effect and traffic conditions may be considered to understand the influence of those effects to the exposure and risk of accidents.

\section{References}

[1] Margie, P., Scurfield, R., Sleet, D., Mohan, D., Hyder, A. A., Jarawan, E., et al., ed. 2004. World Report on Road Traffic Injury Prevention. United Nations: World Health Organization.

[2] World Health Organization. 2009. Road Safety in Western Pacific Region-Call for Action. United Nations: World Health Organization.
[3] Mitchell, R., Driscoll, T., and Healey, S. 2004. "Work Related Road Fatalities in Australia." Accident Analysis and Prevention 36: 851-60.

[4] Salminen, S. 2000. "Traffic Accidents during Work and Work Commuting." International Journal of Industrial Ergonomics 26: 75-85.

[5] Clarke, D. D., Ward, P., Bartle, C., and Truman, W. 2005. Road Safety Research Report No.58: An In-depth Study of Work-Related Road Traffic Accidents. School of Psychology, University of Nottingham.

[6] Chapman, P., Roberts, K., and Underwood, G. 2000. "A Study of the Accidents and Behaviours of Company Car Drivers." In Proceedings of the 10th Seminar on Behavioural Research in Road Safety, 61-73.

[7] Al-Haji, G. 2005. Towards a Road Safety Development Index (RSDI): Development of an International Index to Measure Road Safety Performance. Sweden: Institute of Technology Linköping.

[8] Harrison, W. A., and Christie, R. 2005. "Exposure Survey of Motorcyclists in New South Wales." Accident Analysis and Prevention 37: 441-51.

[9] Gera, S., and Kuhn, P. 1981. "Occupation and the Journey to Work: Some Further Analysis." Socio Economic Planning Science 15: 83-93.

[10] Social Security Organization. 2009. Annual Report 2009. Malaysia: Social Security Organization.

[11] RPM (Royal Police Malaysia). 2009. Statistical Report Road Accident Malaysia 2009. Traffic Branch, Kuala Lumpur, Malaysia.

[12] NGO (Non-Governmental Organization) Unit. 2009. Report: Industrial and Commuting Accidents 2009. Malaysia: Social Security Organization. 